\title{
A Cross Sectional Study on Morphological Pattern of Anemia
}

\author{
${ }^{1}$ Dr.U.Parameswari Babu, ${ }^{2}$ Dr.B.V.Sai Prasad, ${ }^{3}$ E.Sudhakar Reddy ${ }^{4}$ R V Manasa \\ ${ }^{I}$ (Assistant Professor, Department Of Pathology, Dr.PSIMS\&RF Chinnaoutpalli, India) \\ ${ }^{2}$ (Associate Professor, Department of Pathology, S.V.Medical College Tirupati, India) \\ ${ }^{3}$ (Professor \& HOD, Department of Pathology, Govt. Medical College, Nellore, India) \\ ${ }^{4}$ (Lecturer In Statistics, Department Of Community Medicine, GITAM IMS \&R, Visakhapatnam, India)
}

\begin{abstract}
:
Background:Anemia is a global health problem of immense health significance, affecting persons of all ages and economic groups. Anemia is functionally defined as an insufficient RBC mass to adequately deliver oxygen to peripheral tissue. Developing countries like India; it is more common in pregnant women and in adolescent girls.Objectives:The present study was to emphasize various morphological patterns of anemia and its prevalence in various age groups.

Materials and methods: This was a cross sectional study on 920 complete blood pictures (CBPs), over a period of 2 years from 2010 to 2012 at department of pathology,S.V.R.R.G.G.H \&Sri Venkateswara Medical College, Tirupati, a tertiary health care center. The results wereanalyzed andinterpreted statically.

Results: Of the total 920 hemograms that were studied, 685 were anemic with prevalence of $74.5 \%$. Females were 419 (61.2\%) and Males were 266 (38.8\%), was showing Female preponderancewith Male Female ratio 1:1.6. Most common age group in females was 21-30 years and in males was 51-60 years. Commonest pattern of anemia was observed Microcytic Hypochromicfollowed by Dimorphic and Macrocytic anemia respectively.

Conclusions:The introduction of automated cell counters has initiated a rethink on the conventional classification of routinely encountered conditions such as anemia. Iron deficiency anemia (IDA) is the most common anemia with microcytic hypochromic picture. It occurs in all age groups especially in woman in the reproductive age group.Diagnosing anemia and knowing its pattern is important since it help in directing further investigation, identifying the etiology and most importantly helps in treatment.
\end{abstract}

Keywords: Complete Blood Picture(CBP), Microcytic Hypochromic Anemia, Dimorphic anemia, Macrocytic anemia

\section{Introduction}

In India and other developing countries, nutritional anemia most common clinical health problem. It is estimated that ranges from $33 \%$ to $89 \%$ among pregnant woman and is more than $60 \%$ in adolescent girls. National family health survey -3 (NFHS) ${ }^{(1)} 2005-06$, ministry of health and family welfare govt. of India conducted series of survey based on a sample of households that are representative at national and state level. Survey estimates the prevalence of anemia 55.3\% among women of reproductive age ( nonpregnant,non lactating women) and $24 \%$ of men, $69.5 \%$ in children under 5 years of age. During reproductive life of female, menstrual blood loss, inadequate intake, helminthic infection, pregnancy, parturition and lactation significantly results in negative iron imbalance ${ }^{(2,3,4)}$.

In India and other developing countries, prevalence of nutritional anemia in reproductive age group ranges from $60-80 \%$ compared to $10-20 \%$ in developed countries ${ }^{(5)}$. Whatever its cause, when sufficiently severe anemia leads to certain clinical features. Patients appears to pale, Weakness, malaise and easy fatigability are common complaints. Lowered oxygen content of circulating blood leads to dyspnea on mild exertion. Hypoxia leads fatty change in liver, myocardium and kidney. On occasion, the myocardia hypoxia leads angina, particularly when complicated by preexisting coronary artery disease ${ }^{(6)}$.

\section{Materials and methods}

The present descriptive, cross sectional institutional based study was carried out in patients above 10 years of age who were attended to the clinical pathology department, S.V.R.R.G.H., SRI VENKATESWARA MEDICAL COLLEGE, TIRUPATI. Detailed clinical history of each patient was recorded and thorough clinical examination was performed. Venous blood samples were collected in all patients with aseptic precautions with in EDTA anticoagulant. Hematological Investigations done by using SAHLI's HEMOGLOBINOMETER for $\mathrm{Hb}$ estimation and Red cell indices were calculated by manual methods and also by aid of automatedhematology analyzer (MINDRAY BC3000plus). 
Peripheral blood smear examination was performed on all the patients and stained by Leishman's. Staining characteristics and morphological abnormalities of red cells were observed. The distribution, anisocytosis, poikilocytosis along with white blood cell morphology and platelet morphology were observed. Present study included all in and out patients, males and females of various age groups above 10 years having a low hemoglobin (less than $10 \mathrm{gms} \%$ ) levels werestudied. Patient below 10 years, who werereceived blood transfusion and patients in state of shock were excluded from this study. Study was approved from the institutional ethical committee.

\section{Results}

Total number of Complete Blood Pictures was examined 920, out of which 685 were anemic showing the prevalence of $74.5 \%$. This study was showed female preponderance, with females were $61.2 \%(n=419)$ and males were showed prevalence of $38.8 \%(n=266)$.

In females, most of cases were presented at the age group mainly between 21-30 years followed by 4150 years, with shared percentage of 23 and 10.8. In males, most of cases presented at the age group mainly between 51-60 years followed by $>60$ years with shared percentage of 13.6, and 5.2.

In the present study, most commonmorphological pattern of anemia was observed in examination of peripheral smear was microcytic hypochromic anemia followed by normocytic normochromic, dimorphic anemia and macrocytic anemia which exhibited percentage of 86, 15.4, 9.1 and 4.9 respectively.

Most common anemic pattern wasobserved in our present study was Microcytic hypochromic anemia. With prevalence of $86 \%(n=589)$. This type of pattern of anemia was showed female preponderance. Out of $86 \%$, females were $60.6 \%(n=357)$ and males were $39.4 \%(n=232)$.

In females, most of microcytic hypochromic anemic cases presented at the age group mainly between 21-30 years followed by 10-20 years. Males, presented at the age group between 51-60 years followed by $>60$ years.

Second most common pattern of anemia observed in our present study was dimorphic anemia. Total number of cases was 63 , with prevalence ofthe $9.1 \%$. Females were 46 with prevalence of $6.7 \%$ and males were 17 with prevalence of $2.4 \%$.

In females, most of dimorphic anemic cases presented at the age group between 21-30 years and males, presented at the age group of between 51-60 years.

In our present study we, defined anemia by using the parameters, hemoglobin $(\mathrm{Hb})$ level $(\mathrm{g} / \mathrm{dl})$, hematocrit (\%), with advent of automated analyzer other RBC indices are also used to diagnose the various types of anemia: $\mathrm{MCV}, \mathrm{MCH}, \mathrm{MCHC}, \mathrm{RDW}^{(7,8)}$.

In microcytic hypochromic anemia MCV, MCH,MCHC are decreased and RDW increased. In dimorphic anemia MCV,MCH are decreased but MCHC and RDW shows normal values.In macrocytic anemia MCV and RDW are increased, but MCHC shows normal value.

\section{Discussion}

The introduction of automated cell counters has initiated a rethink on the conventional classification of routinely encountered conditions such as nutritional deficiency anemia. The varied etiology of this condition makes it more difficult to point at the exact etiology on mere morphological grounds alone, which is assessed by individuals. The role of subjective factors in this assessment cannot be ruled out.

Nutritional anemia is more common; Iron deficiency anemia is the most common type met with in routine clinical practice and is of microcytic hypochromic type. It occurs in all age groups but especially in woman in reproductive age group. It is an important cause of chronic fatigue and ill health.

In our study, the overall prevalence of anemia was found to be $74.5 \%$.

A lower prevalence was observed in the studies of Rana et $\mathrm{al}^{(9)}$, Seshadri et al ${ }^{(10)}$ and Dorothy et al ${ }^{(11)}$ where overall prevalence of anemia was found to be $60 \%, 63 \%, 64 \%$ respectively.

Among $74.5 \%$, male were found to be $38.8 \%$, female were $61.2 \%$. Where as a lowerprevalence was noticed in the study conducted by National Family Heath survey (NFHS-3) ${ }^{(1)} 2005-06$ in India, with prevalence $55 \%$ of anemia in Females, and $24 \%$ in Males.

The high prevalence observed in the present study would be related to the low socioeconomic status, poor nutrition, lack of awareness and lack of education.

In the present study, most common pattern seen in blood film examination was Microcytic hypochromic anemia followed by dimorphic anemia and Macrocytic anemia. These patterns showed values of $86 \%, 9.1 \%$ and $4.9 \%$ respectively.

In a study done by M.Bukar et $\mathrm{al}^{(12)} 2009$, Microcytic hypochromic anemia was the commonest pattern with $64.9 \%$ followed by Dimorphic anemia with $34.7 \%$ and Macrocytic anemia with $0.4 \%$. 


\begin{tabular}{|l|c|c|}
\hline \multicolumn{3}{|c|}{ Blood Film } \\
\hline Microcytic-Hypochromic & $64.9 \%$ & Present study \\
\hline Dimorphic & $34.7 \%$ & $86 \%$ \\
\hline Macrocytic & $0.4 \%$ & $9.1 \%$ \\
\hline
\end{tabular}

\section{Conclusions}

Iron deficiency anemia is the most common type affecting especially in women with reproductive age group. In our present study, adolescent womenwere found to have high prevalence of anemia.Since anemia is more prevalent among low socio-economic groups, the higher diagnostic tests lead to financial burden to the patients. The study of basic blood parameters and peripheral smear examination are less expensive and mandatory in the work up of anemia.Morphological patterns of anemia reflects the underlying etiology, the study of which would ensure benefits in the early detection and appropriate treatment. Iron deficiency anemia being a nutritional anemia which can be prevented byimproving nutritional status, creating awareness and educating people.

\section{References}

[1]. National Family and Health survey (NFHS-3), IIPS ( 2005-2006)

[2]. BC Mehta, KusumJhaveri, JC Patel. Anemia in Pregnancy. Indian J Med sci 1971; 25:301-7.

[3]. Henderson PA, Hillman RS. Characteristics of Iron Utilization in Man Blood 1969;34:357.

[4]. Hibbard BM, Hibbard EE. Folate Metabolism and Pregnancy. Brit Med Bull 1968;24:10

[5]. DC Dutta. Textbook of Obstetrics $6^{\text {th }}$ Edition. Central 2009

[6]. Vinay Kumar, Abul K Abbas, Nelson Fausto. Robbins \&Contran Pathologic Basis of Disease $8^{\text {th }}$ Edition. Saunders; 2009.

[7]. G. Richard Lee, John Foerster, John Lukens, FrixosParaskevas, John P Geer, George M Rodgers. Wintrobe'sClinicalHaematology. $11^{\text {th }}$ Edition. Williams \&wilkins; 2003

[8]. David Bessman, Ridgway Gilmer, Frank H Gardner. Improved Classification of Anemias by MCV and RDW. Am J Patho 1983; $89: 322-26$

[9]. Rana T. Age at menarche; Nutritional status and other associated factorsin urban Hyderbad girls. Ph.D. Thesis submitted to National Institute ofNutrition, Hyderbad-1983.

[10]. Seshadri: a data base iron deficiency anemia in India. Prevalence, etiology,consequences and strategies for control, task force for micronutrientsmalnutrition control, Department of Women and Child Development,Ministry of Human Resource, Development, New Delhi-1996.

[11]. Dorothy J.V.Hugh S.B, George S. Melah, Aliyu U., E1-Nafaty,Michael J.G. and Robert H.Glew. Nutritional factors Associated with Anemia in pregnant women in Northern Nigeria. J Health PopulNutr 2006; 24:1-7.

[12]. M.Bucker, B.M.Audu, H.M. Sadauki, A.U.Elnafaty, A.G. Mairiga. Prevalence of Iron deficiency and Megaloblstic anemia at Booking in a Secondary health facility in North Eastern Nigeria. Niger Med J, Vol. 50 No 2, April -June, 2009

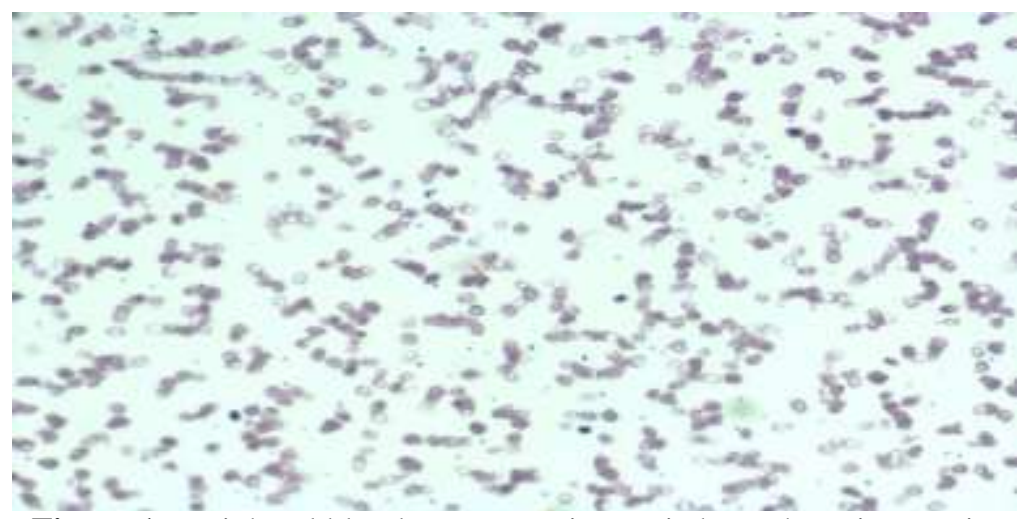

Figure 1: peripheral blood smears: Microcytic hypochromic anemia

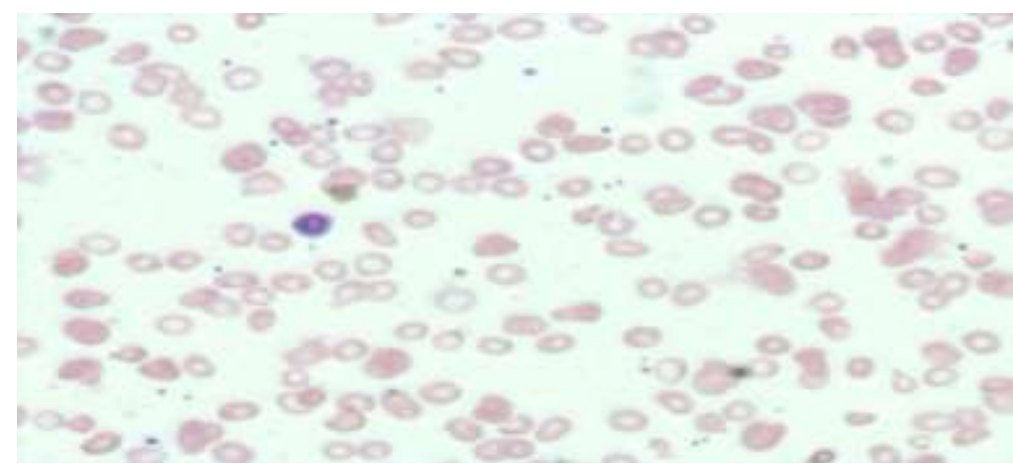

Figure 2: peripheral blood smears:macrocytic anemia-Macrospherocytes 


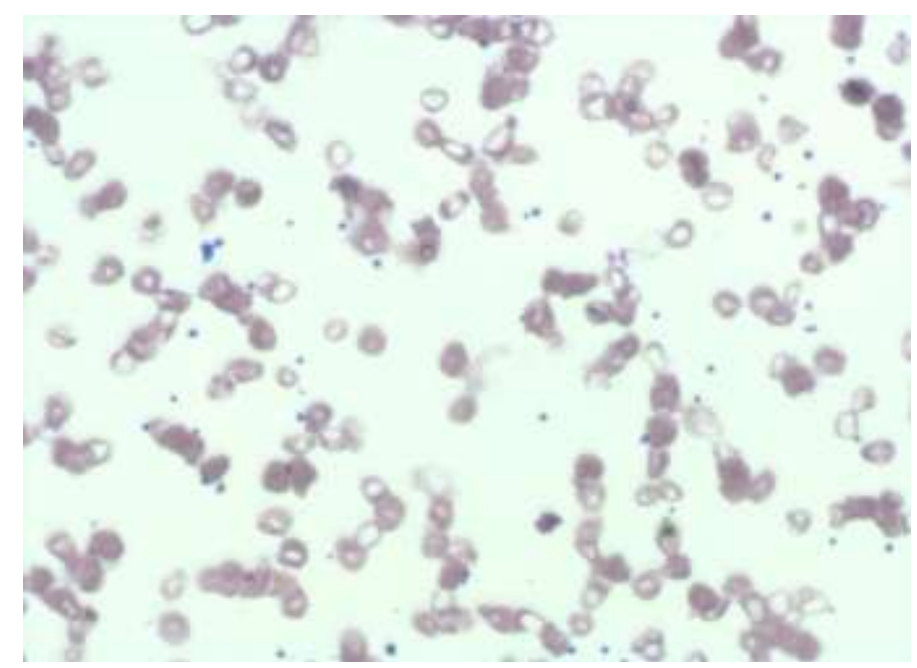

Figure 3: Peripheral blood smears:Dimorphic anemia

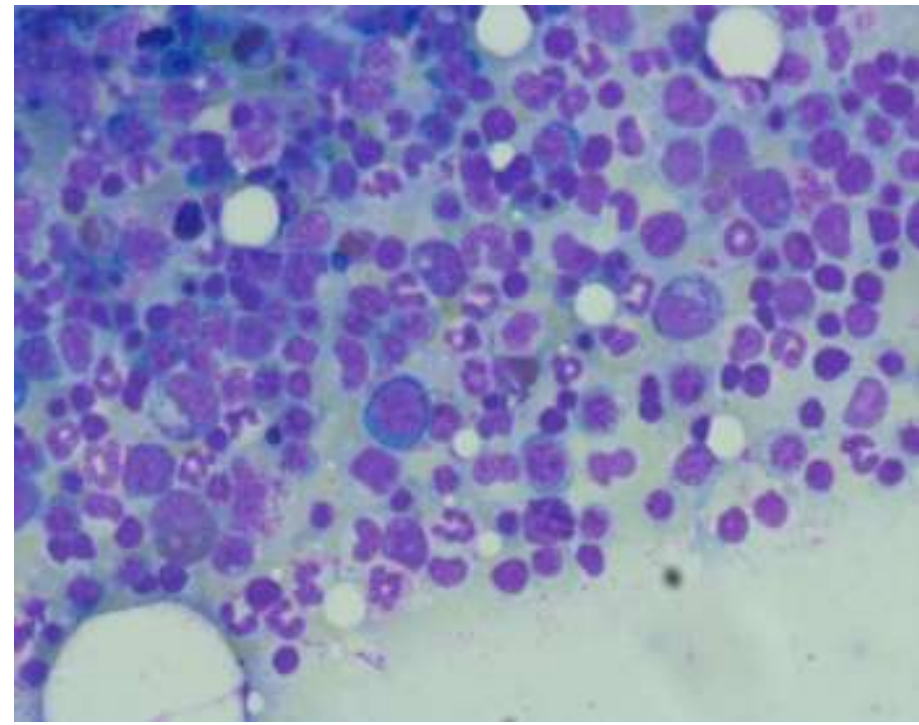

Figure 4: Bone marrow picture - Megaloblastic anemia (Normoblastswithopen sieve-like nucleus)

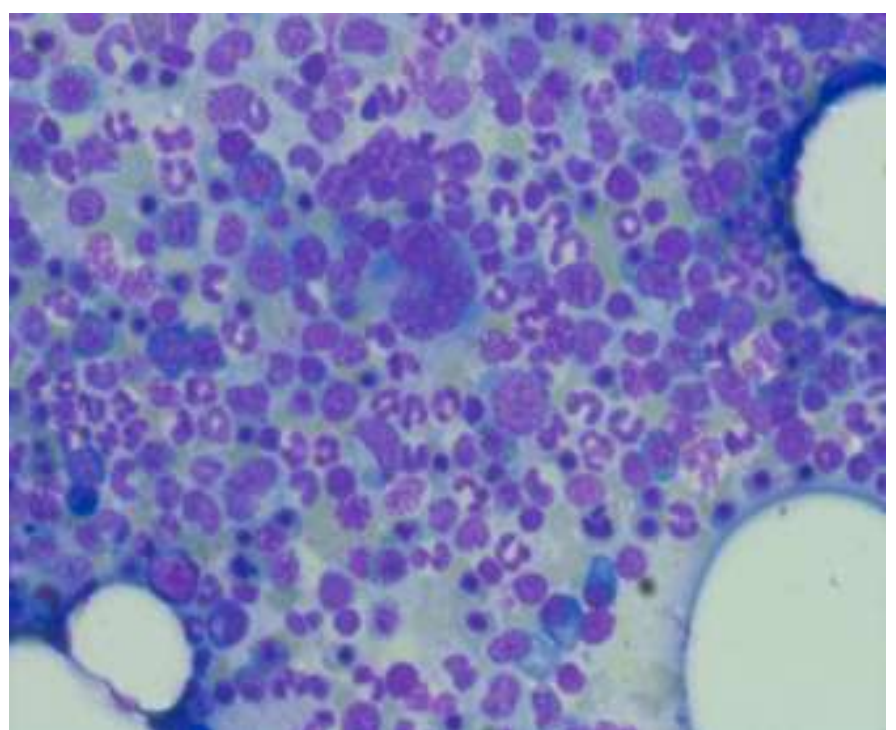

Figure 5: Bone marrow - Megaloblastic anemia, showing giant metamyelocyte (Normoblasts with open sieve-like nucleus) 